Supplement of The Cryosphere, 13, 469-489, 2019 https://doi.org/10.5194/tc-13-469-2019-supplement (C) Author(s) 2019. This work is distributed under the Creative Commons Attribution 4.0 License.

(c) (1)

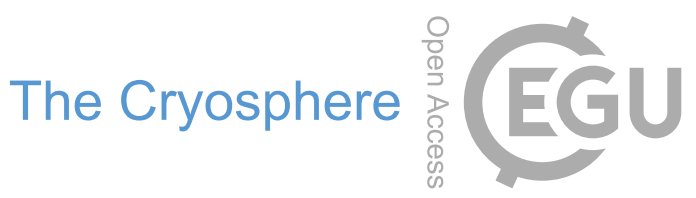

Supplement of

\title{
Robust uncertainty assessment of the spatio-temporal transferability of glacier mass and energy balance models
}

Tobias Zolles et al.

Correspondence to: Tobias Zolles (tobias.zolles@uib.no)

The copyright of individual parts of the supplement might differ from the CC BY 4.0 License. 


\section{Supplement}

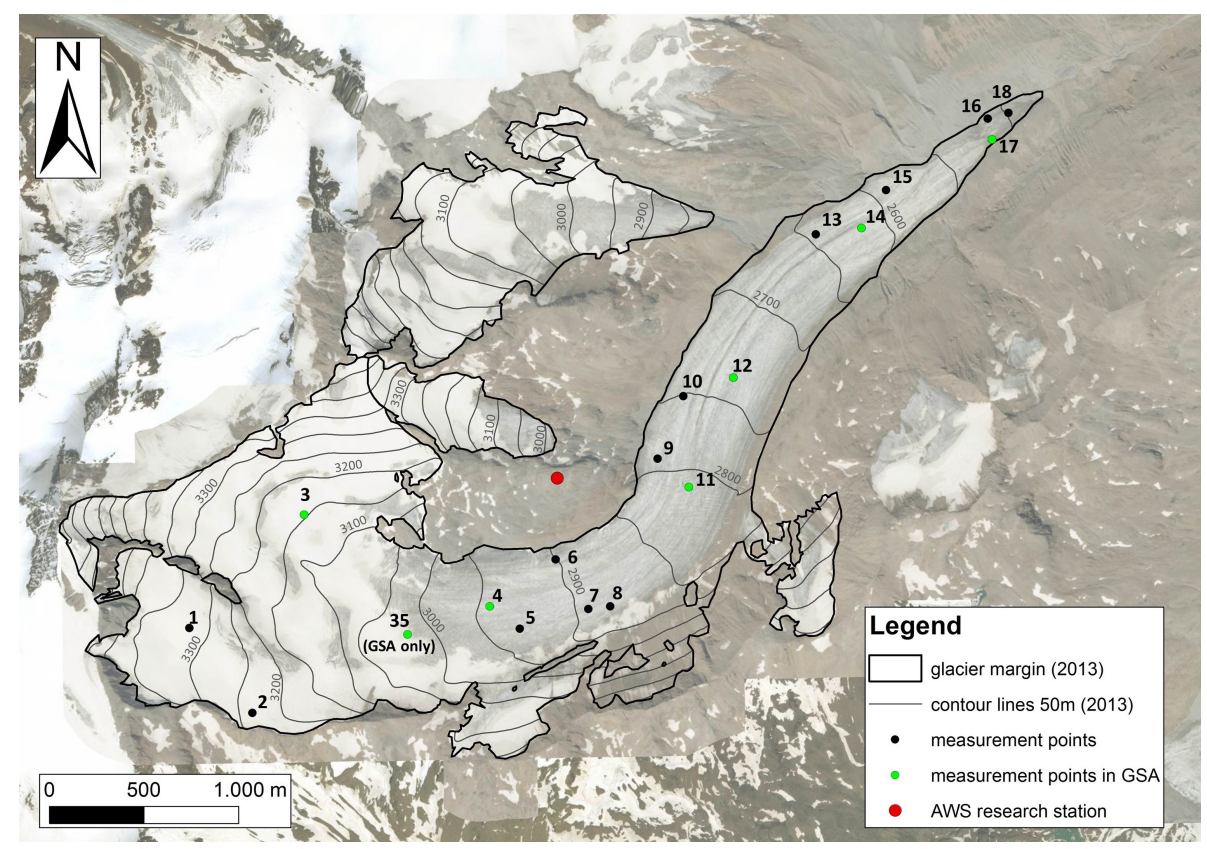

Figure 1. Hintereisferner is the larger glacier used in this study with $6.7 \mathrm{~m}^{2}$. The study uses the mass balance data of 18 stakes for the Optimization (1-18). Six of these stake locations are used for the sensitivity analysis (green dots). The grid point corresponding to location 35 served as 7th point in the GSA, but only mass balance data for two years is available and it is not used for the optimization. The weather station which supplied the forcing data for the model is marked red. 


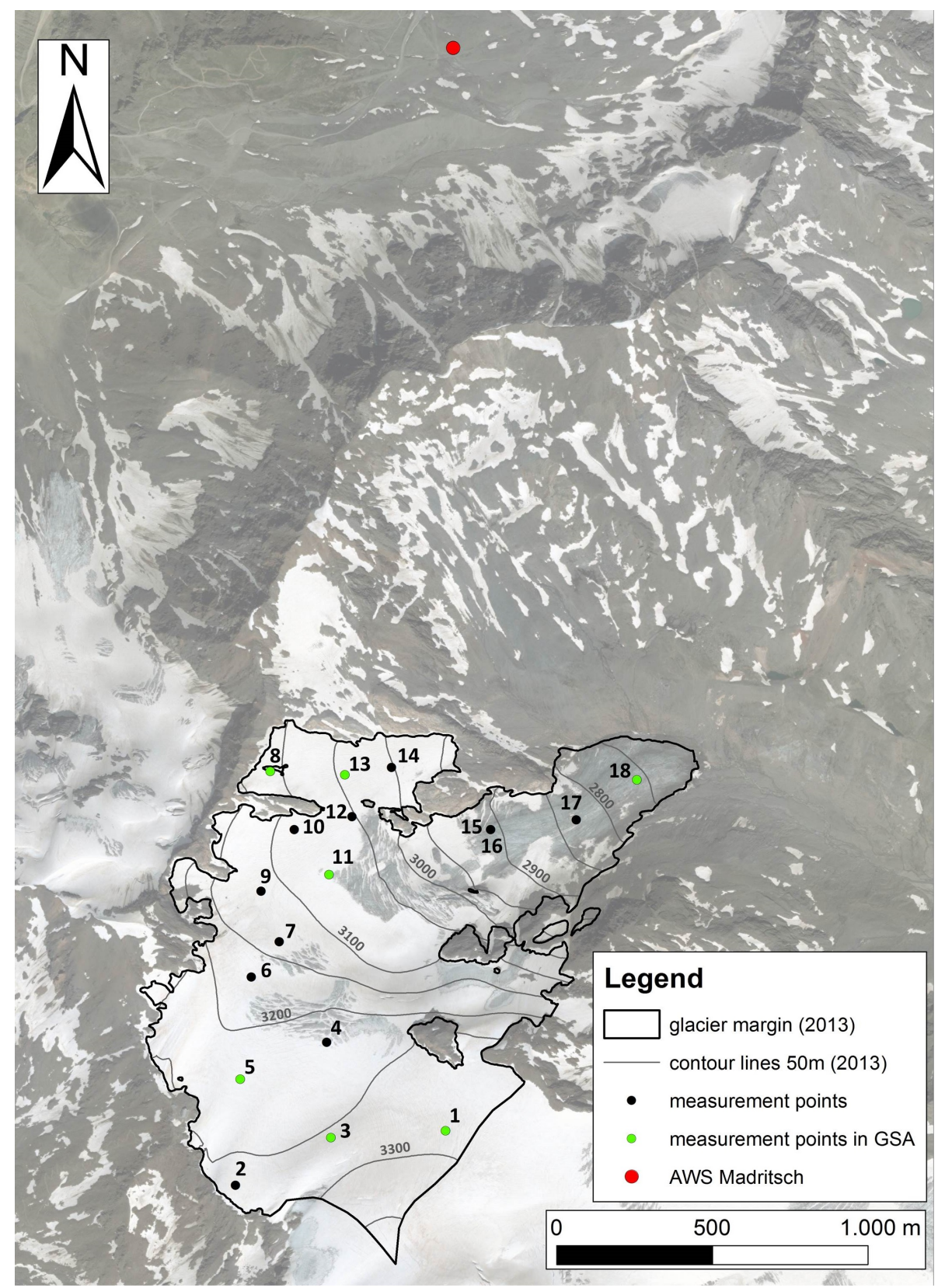

Figure 2. On Langenferner 18 stake locations were used for the model calibration, with the green dots also being used for the GSA. The glacier area is $\approx 1.6 \mathrm{~km}^{2}$ The weather station of Sulden-Madritsch is located around $2 \mathrm{~km}$ to the north. 

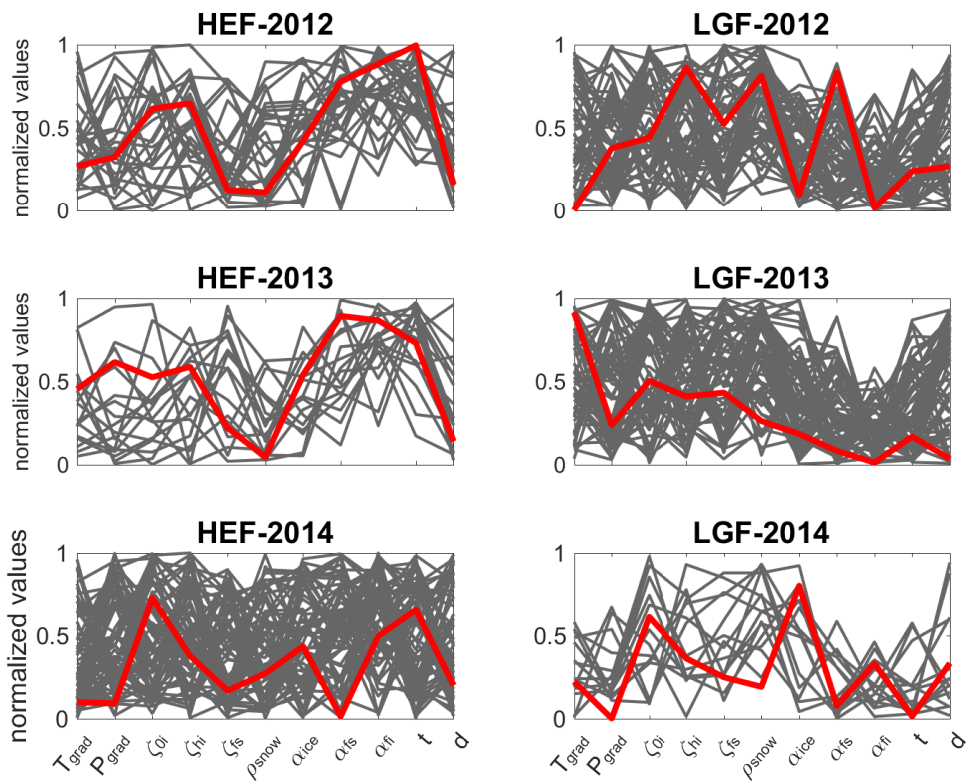

Figure 3. Parameter settings for the individual years on both glaciers. The sizes of the solution space is varying between 17 and 61 members, with the compromise solution indicated in red. The parameters span almost over the whole parameter space. Snow albedo related values are slightly more confined, with larger values on HEF than on LGF for fresh snow and firn albedo and the timescale. 

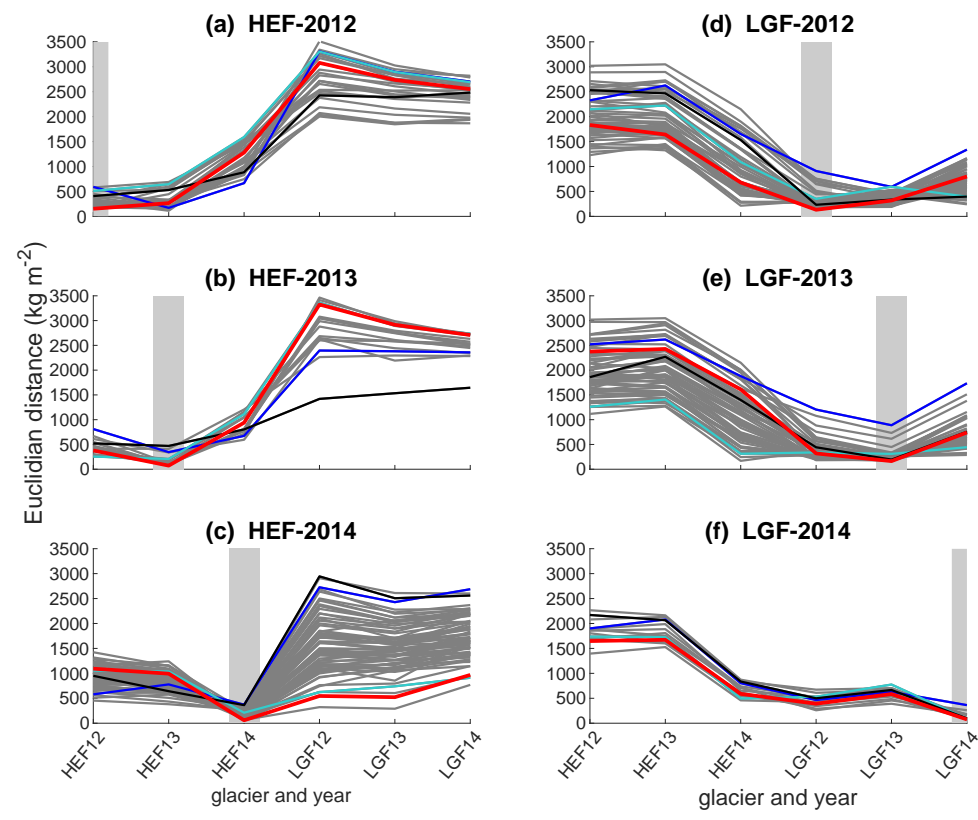

Figure 4. The euclidean distance of the optimal solutions of each year were applied to all six glacier/summer cases. The curves in the individual panels are the optimal solutions for the respective year (HEF (a-c), LGF (d-f)). The compromise solution, which has the lowest euclidean distance, is shown in red the best solution in respect to the individual objectives are: MADlow (blue), MADtop (cyan) and BIAS (black). The performances out of the calibration period vary depending on the year and the individual solution. 

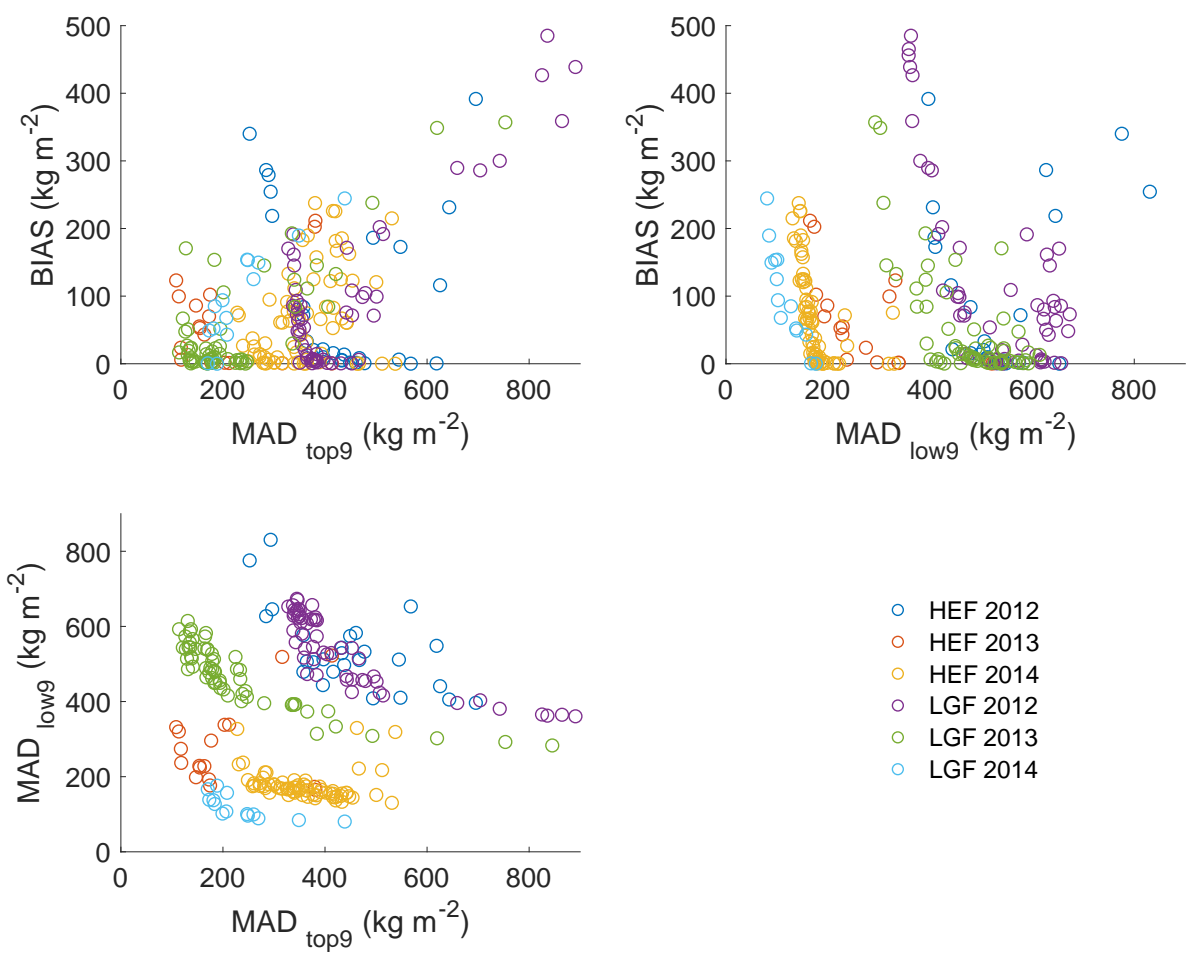

Figure 5. The Pareto space for all years and glacier show a distinct variation of the model performance over the years. 


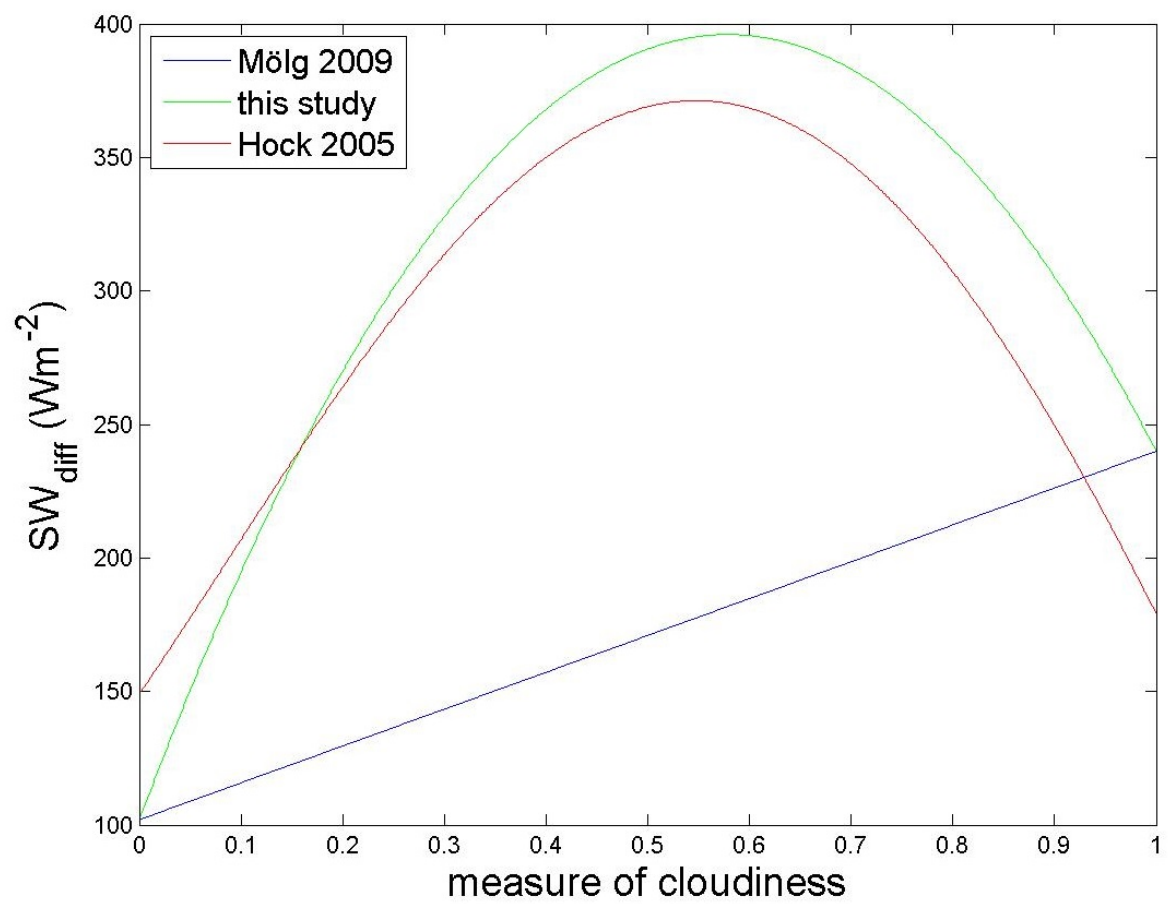

Figure 6. The diffuse radiation for a day with a total potential radiation of $1200 \mathrm{~W} \mathrm{~m}^{-2}$ in respect to the cloud cover fraction. The green curve is the new parametrization increasing the portion of diffuse radiation, rather than the diffuse radiation (blue) (Mölg et al., 2009). This is compared with the adapted parametrization by Hock and Holmgren (2005) based on measurements of global and diffuse radiation. Exact values are not to be analyzed here, as they depend on the choice of the parameters $k$ and $p_{\text {diff } f}$. 


\section{References}

Hock, R. and Holmgren, B.: A distributed surface energy-blaance model for complex topography and its application to Storglaciaären, Sweden, Journal of Glaciology, 51, 25-36, doi:10.3189/172756505781829566, 2005.

Mölg, T., Cullen, N. J., and Kaser, G.: Solar radiation, cloudiness and longwave radiation over low-latitude glaciers: Implications for massbalance modelling, Journal of Glaciology, 55, 292-302, doi:10.3189/002214309788608822, 2009. 